\title{
JACAREZINHO: paradoxo de prosperidade e miséria*
}

\author{
Marcus José Takahashi Selonk
}

\author{
Especialista em Sociologia, Saúde Pública e Saneamento e Vigilância Sanitária.
}

\begin{abstract}
O presente trabalho tem como objetivo principal estudar de que forma as relações de trabalho características da lavoura cafeeira, representadas principalmente pelo colonato, substituído posteriormente pelo trabalhador volante bóia-fria, podem ser associadas ao surgimento do município de Jacarezinho, seu desenvolvimento e, mais recentemente, sua estagnação econômica. Além disso, o apanhado bibliogxáfico apresentado propõe uma sequiência futura, onde a temática será aprofundada, detalhada, completando as idéias aqui apresentadas.
\end{abstract}

Palavras-chave: Jacarezinho; norte do Paraná; Norte Pioneiro; cafeicultura; capitalismo.

\section{APRESENTAÇÃO}

$\mathbf{O}$ tema do presente trabalho diz respeito ao desenvolvimento da cafeicultura no Paraná, especialmente na região do denominado

Norte Velho (ou Norte Pioneiro) e, mais especificamente, no município de Jacarezinho. Na realidade, esta região, que faz limite com o Estado de São Paulo, teve seu desenvolvimento baseado na expansão da cafeicultura paulista, com um tipo de ocupação espontânea que data do início do século, tendo como pólo principal a cidade de Jacarezinho.

Entretanto, depois de quase um século, a cidade de Jacarezinho e o seu meio rural circundante passaram por profundas transformações, causadas pelas crises sucessivas da cafeicultura e por sua substituição por outras culturas como, por exemplo, a cana-de-açúcar, ${ }^{1}$ e pela pecuária. Decorrente deste processo, há uma reestruturação das relações de trabalho no meio rural circundante, com substituição do colonato existente nas grandes fazendas de café pela mãode-obra volante característica da cultura de cana-de-açúcar.

Com isso, mais recentemente a cidade de Jacarezinho recebeu um grande contingente de migrantes ex-colonos do café, que habitam seus bairros mais pobres e que se deslocam cotidianamente para trabalhar nas grandes usinas de açúcar, provocando um impacto socioeconômico bastante significativo na dinâmica das relações entre meio rural e meio urbano (inchaço da cidade, aumento da pobreza, surgimento de vilas e favelas, além do crescimento das já existentes) e estagnação econômica do município. Temos que destacar, também, que a mão-de-obra ocupada pelas usinas de canade-açúcar é sazonal, agravando ainda mais o problema.

Além desses ex-colonos que migraram para a cidade, há ainda um grande número de pessoas que deixaram o município em busca de melhores oportunidades (conforme comprovaremos através dos dados censitários do IBGE).

Assim, a preocupação central do presente estudo é compreender as principais mudanças pelas quais o município de Jacarezinho passou quando da substituição da cultura do café por outras culturas e, também, de que forma esta substituição ocasionou uma reestruturação nas relações de trabalho, bem como nas relações entre cidade e campo, tentando com isso entender melhor o processo de progressiva estagnação socioeconômica que o município vem sofrendo nas últimas décadas, apesar das recentes tentativas de transformá-lo em pólo educacional e de prestação de serviços.

Nesse sentido, a história da cultura cafeeira e as mudanças recentes no município de Jacarezinho não podem ser separadas das transformações pelas quais passaram o Brasil, o Paraná e o Norte do Paraná, na medida em que fazem parte de um processo mais amplo, qual seja, o do desenvolvimento do capitalismo nacional e, especialmente, do meio rural brasileiro.

Ao se tentar estabelecer os nexos existentes entre esse processo mais amplo de desenvolvimento do capitalismo nacional e regional, acredita-se que a presente reflexão pode estar contribuindo com os estudos existentes sobre as trans-

* O texto é uma adaptação da monografia de mesmo nome apresentada como trabalho de conclusão do curso de Especialização em Sociologia e Sociologia da Educação, da UEL, em novembro de 1997, sob orientação da professora Ana Maria Chiarotti de Almeida.

Rev. Mediações, Londrina, v. 4, n. 2, p.76-87, jul./dez. 1999 
formações mais recentes da região do norte do Paraná, e, especialmente, do chamado Norte Pioneiro.

Ainda, ao se propor elucidar essas mudanças, acredita-se estar desvendando algumas características da realidade socioeconômica atual de municípios que, a exemplo de Jacarezinho, foram a "porta de entrada" da cafeicultura paranaense, experimentando em décadas passadas grande desenvolvimento e que, no presente, passam por um processo de estagnação.

\section{O CAFÉ E SEU ITINERÁRIO NO BRASIL}

De origem árabe e etíope, o café percorreu um longo itinerário, num período compreendido entre 1500 e 1700 , até ser servido nos elegantes cafés parisienses. Nesse período, além de suas comprovadas características medicinais e estimulantes, associadas ao tabaco, era tido como símbolo de prazer, elegância e condição social. Dessa forma, em 1710 já havia em Paris algumas centenas de cafés públicos.

Em curto espaço de tempo o café passou a ser visto pelos europeus como um substituto do chá da Índia, cujo comércio era, naquela época, monopolizado pelas casas importadoras inglesas.

Para fugir às imposições comerciais inglesas em relação ao chá e para atender uma demanda que aumentava dia a dia, provavelmente entre 1700 e 1710 o oficial francês Gabriel de Clieu introduziu a cultura de café nas terras de possessão francesa, entre elas a colônia de Martinica e a Guiana Francesa.

Daí para o Brasil, contam os historiadores que:

"o comerciante português Francisco de Mello Palheta, em 1927, chefiando uma missão comercial do Reino cujo objetivo era ativar negócios com a desconhecida Amazônia, ganhou de presente da esposa do governador da Guiana Francesa, algumas mudas da planta que se tornava famosa em toda a Europa. (...) Outros vêm na expedição de Palheta um objetivo bem definido da coroa de Portugal: obter para sua colônia de clima quente a cultura de um produto de crescente aceitação.” (CMNP, 1975, p.14-15)

Independente do motivo que ocasionou sua entrada no país, é certo que os primeiros cafeeiros surgiram na cidade de Belém do Pará em meados do século XVIII.

Embora nessa época ainda não se atribuísse ao café importância econômica e seu cultivo fosse coisa de quintal, sendo vendido em quitandas, durante o século seguinte, provavelmente entre 1727 e 1820 , o café foi cultivado em toda a faixa litorânea, seguindo um sinuoso caminho:

"disseminou-se pelos arredores de São Luiz do Maranhão, ganhando a Zona da Mata e espalhandose ao longo da borda marítima de Pernambuco, Alagoas, Sergipe, Bahia e Espírito Santo. Encontrou também grande aceitação no Rio de Janeiro e em
Minas Gerais, difundindo-se pelo Vale do rio Paraíba na direção de São Paulo". (idem, p.15)

E foi este café, cultivado em fundo de quintal e vendido em quitandas, que se espalhou pelo Brasil. Logicamente que num país onde a base da economia girava em torno de ouro, açúcar, aguardente e couro, o comércio de café nem de longe demonstrava o potencial econômico que viria a ter.

Com a grave depressão econômica vivida pelo país no início do século XIX, mais precisamente por volta de 1820 , os diversos produtos que representavam nossa base comercial na época, principalmente os derivados da canade-açúcar e a pecuária, mergulharam numa vertiginosa crise de comercialização. Esta situação fez com que os agricultores brasileiros procurassem no café uma alternativa de substituição viável e compatível com as demandas do mercado internacional.

E acertaram. Em 1830 o café já ocupava o terceiro lugar na pauta das exportações brasileiras (18\%), perdendo apenas para a cana-de-açúcar e para o algodão. Em 1850 o café já ocupava o primeiro lugar nas exportações, com $40 \%$.

Em constante desenvolvimento, a cultura de café estendeu-se pelo vale do rio Paraíba e adentrou o Estado de São Paulo. Nesse período (por volta de 1850), é significativo o fato de que, ao ser cultivado nas imensas manchas de terra roxa da região de Campinas, os índices de produção por pé de café chegavam a representar o dobro ou o triplo daqueles obtidos nos demais tipos de solo. Isto propiciou grandes lucros, que fizeram surgir dois fatores que impulsionaram o desenvolvimento da economia capitalista no Brasil:

"disponibilidade financeira para investimentos e demanda de meios para atender a comercialização deste produto agrícola. Havia cada vez mais café e havia necessidade de transportá-lo. (...) Havia recursos disponíveis e a vontade de aplicá-los. (...) Havia sobras de dinheiro e o interesse em destiná-las diversificadamente. Dessa ocorrência concomitante de fatores positivos surgiram as estradas de ferro, as usinas de eletricidade, as indústrias, a hegemonia política". (idem, p.19-20)

Esta conjugação de fatores, conforme veremos no decorrer deste trabalho, seria de fundamental importância no desenvolvimento da região norte do Paraná.

O desenvolvimento da região de terra roxa do Estado de São Paulo, cujo pólo central poderia ser considerado a cidade da Campinas, foi assustador. Em 1860 as plantações de cana-de-açúcar e gêneros alimentícios já tinham sido totalmente substituídas por imensos cafezais. Dessa forma, o progresso, oriundo das divisas do café, alastrou-se para municípios como Piracicaba, Rio Claro, São Carlos e Jaú.

Todo este futuro não poderia mais ser transportado em lombo de burro até o porto de Santos, como o era até esta época. Necessitava-se de um transporte mais rápido e prático, e os ingleses o tinham: as estradas de ferro.

"A máquina a vapor e os geradores de energia elétrica começavam a ser produzidas (sic) e precisavam ser 
vendidas (sic) ao exterior. As usinas siderúrgicas inglesas fabricavam aço, e muitas indústrias mecânicas dedicavam-se a transformá-lo em trilhos, pontes metálicas e máquinas para a indústria de transformação. $O$ que se verificava era: de um lado uma demanda segura de transporte; do outro, na Inglaterra, a existência de capitais disponíveis para investimento, de máquinas para serem vendidas. (...) Nós tínhamos o que transportar, eles tinham como transportar". (idem, p.18)

Então, em 1886, surgia a São Paulo Railway, ligando a cidade de Jundiaí ao porto de Santos. É fácil imaginar o que isto significou. Uma viagem até o litoral, em lombo de mula, que demorava até duas semanas, passou a ser feita em algumas horas. Se o desenvolvimento já vinha literalmente "a galope", passou então a desprender uma velocidade extraordinária. O resultado não poderia ser outro: a São Paulo Railway, associada a uma outra empresa canadense que instalou na região a Light, no ramo de energia elétrica, transformaram a região num dos maiores pólos industriais do mundo.

O café, a partir daí, sempre esteve associado às estradas de ferro, formando uma parceria que era sinônimo de sucesso. Em 1872 a São Paulo Railway prolonga-se até Campinas, constituindo a Cia. Paulista de Estradas de Ferro. Em 1873 construiu-se a Ituana. Em 1875, os primeiros trechos da Sorocabana e da Mogiana. Em 1877 a futura Central do Brasil chegava a Queluz. Em 1883, chegou a Ribeirão Preto.

Esta proliferação de estradas de ferro foi de fundamental importância na constituição de diversas e prósperas cidades:

"Ao longo das ferrovias fundavam-se prósperas cidades, enquanto os fazendeiros dos arredores - contando com mais fácil e seguro meio de transporte podiam se arriscar ao abandono de uma inexpressiva agricultura de subsistência para se lançar ao cultivo de um produto de exportação, facilmente aceito nos mercados internacionais e, por isso, capaz de propiciar grandes lucros". (idem, p.21)

A partir daí, com toda a característica de pioneirismo demonstrada pela cultura cafeeira, de que trataremos a seguir, sua entrada no Estado do Paraná era apenas questão de tempo.

\section{A CONJUNTURA ECONÔMICA DO CAFÉ NO BRASIL E UM PANO- RAMA HISTÓRICO GERAL DA CA- FEICULTURA PARANAENSE}

\subsection{O período de "defesa" do café}

A cafeicultura no Brasil viveu quatro períodos distintos $^{2}$ e perfeitamente identificáveis: período de incentivo à produção (1906 a 1929); período de depressão econômica
(1930-1944); período dinâmico (1945-1970); e o período que ainda estamos atravessando, de reestruturação e viabilização de novas opções à cafeicultura (de 1971 aos dias de hoje).

Em fins do século XIX e começo do século XX, quando o extravasamento da extensão dos cafeeiros paulistas atingiu o Paraná, a cafeicultura brasileira estava ameaçada por dificuldades decorrentes do aumento excessivo da oferta.

Entre 1906 e 1924 foram realizadas três intervenções mediante a retirada de café do mercado, com vistas na melhoria do preço, denominadas operações valorizadoras (1906 a 1914, 1917 a 1920 e 1921 a 1924), persistindo após 1924 no que foi chamado "defesa permanente". Esse período corresponde, no Paraná, à primeira conjuntura favorável à expansão cafeeira.

Apesar de todas estas medidas de valorização implantadas pelo governo brasileiro no intuito de "defender" a cafeicultura no Brasil, os fazendeiros sabiam que haveria um excesso de produção e esta valorização temporária seria apenas artificial.

Com o excesso de produção no Estado de São Paulo e a política de "valorização artificial" implantada com a retirada de café do mercado, acelerou-se, por parte dos grandes cafeicultores paulistas, a busca de novas terras, o que ativou a especulação de compra e venda de terras no Paraná. Isto significou a expansão do plantio, com aumento de produção nos anos seguintes e abertura de "frentes pioneiras". 3

\subsection{O tempo das "vacas magras": período recessivo para a cafeicultura}

Este período foi marcado por profunda depressão econômica, ocasionada pela superprodução, e pela derrocada do sistema implantado pela defesa permanente, coincidindo com a crise que se seguiu à "quebra" da bolsa de Nova York e, posteriormente, pelas dificuldades oriundas da Segunda Guerra Mundial.

A política cafeeira foi exercida no sentido de regular a oferta e estabelecer um "equilíbrio estatístico" através de mecanismos como incineração, proibição de novos plantios, instituição de taxas de exportação e quotas retidas, numa clara intervenção do Estado. Esta crise foi deflagrada num momento em que o Brasil tinha em estoque 20 milhões de sacas, quase a totalidade financiada pelos institutos de defesa.

Com esta recessão, muitos cafeicultores abandonaram seus cafezais, especialmente os menos produtivos. Outros se dirigiram para novas terras paranaenses; alguns diversificaram sua lavoura e outros, ainda, fracionaram suas propriedades. Em função da proibição de novos plantios, mas sobretudo pelo desestímulo dos preços, não houve grande interesse em plantar extensos cafezais como havia ocorrido na década de 20. Continuava a busca por novas terras, porém sem a euforia de épocas passadas.

Nos últimos meses de 1930 a situação era de desespero. Com a revolução de outubro de 1930 e a conseqüente posse do governo revolucionário, o Estado adotou a estratégia de comprar todos os estoques para liberação em safras futuras, mesmo que com isso ocorresse a queda dos preços. 
Medidas complementares adotadas em 1931 estabeleceram a compra e incineração do café retido e a proibição de plantio por cinco anos, além da cobrança de um imposto de $20 \%$ para cada safra, podendo ser modificado no ano seguinte.

Como os estados ainda mantinham uma relativa autonomia, atendendo a veementes reclamações do Paraná as regiões produtoras estabeleceram a proibição do plantio apenas para aqueles em que houvesse uma quantidade plantada superior a 50 milhões de pés de café, o que beneficiou sobremaneira o Estado do Paraná.

Nesse período (1931) ocorreu o início da intervenção sistemática do governo na economia, com a criação do Conselho Nacional do Café (CNC), em 1931, e do Departamento Nacional do Café (DNC), em 1933.

Em 1934, com a prática do equilíbrio estatístico em vigência, que recorria à incineração como meio de ajustar a oferta, iniciou-se uma campanha para melhoria de qualidade, incentivando a produção de cafés finos. A política de sustentação através da incineração contribuiu para que a eficácia da política brasileira para o setor fosse desacreditada.

Mesmo na contramão da história, quando a maioria dos estados cafeeiros desestimulava sua produção, o governo paranaense mantinha esforços para continuar a proteção à cafeicultura no estado. Desejava expandir as plantações sem limite determinado e a abolição das taxas em vigor era considerada um meio de promover o plantio. Mas esse não era, na realidade, o motivo principal.

"As grandes concessões de terras feitas pelo Estado a particulares durante a década de 20 eram uma das fontes de renda mais promissoras. Loteadas as terras, os impostos de transferência rendiam tanto quanto a própria produção agrícola. Se houvesse de fato a proibição do plantio de cafeeiros, centenas de pequenos lavradores que se dirigiam ao Paraná por esta época, procedentes principalmente de São Paulo, deixariam de adquirir terras". (CANCIAN, 1981, p.32)

O Paraná procurava atrair o café porque, apesar das dificuldades conjunturais, era o produto que mais representava divisas para o Brasil, sendo, conseqüentemente, o setor agrícola mais defendido pelo governo. Além disso, a ausência de lucros existia para as grandes propriedades, em terras cansadas e cafeeiros velhos, o que não era absolutamente a situação do estado naquele momento.

Além disso, o café não era produto exclusivo: as pastagens, o algodão e as lavouras temporárias compunham um quadro que diferenciava a agricultura paranaense da de outros estados. Não aderíamos, àquela época, à monocultura nas grandes propriedades. Então, se por um lado São Paulo limitava sua produção, por outro os lavradores paulistas migravam para o Paraná.

A pressão imposta pelo "preço máximo" estipulado pelos Estados Unidos levava o país a um "sacrifício de nossos próprios interesses", onde vendíamos o nosso produto a um preço de remuneração insuficiente. Em 1937, definitivamente, o Brasil não conseguia mais suportar esta carga, levando a uma política de "luta comercial" contra os Estados Unidos: "O Brasil levantou as restrições às exportações, quer baixan- do os preços, quer permitindo a saída de cafés do tipo inferior, proibida desde agosto de 1930". (CANCIAN, 1981, p.34)

Essas medidas obtiveram um resultado satisfatório, havendo um aumento, de um ano para o outro, na ordem de 5.079.279 sacas. (DNC apud CANCIAN, 1981, p.35)

Em 1939, em virtude da guerra na Europa, o consumo se reduziu em quase 1 milhão de sacas. No entanto, observava-se no Brasil um acréscimo nas importações na ordem de 140 mil sacas, mas nunca os preços haviam caído tanto. Em 1940, todo o mercado europeu e parte do Norte da África foram fechados para o café, fazendo com que o Brasil perdesse cerca de $41 \%$ de seus mercados tradicionais.

Em 1942, grandes geadas dizimaram as lavouras, principalmente as do Paraná e as de São Paulo. Assim, em 1943 foi retirada a proibição de plantio. A quota de equilíbrio foi reduzida para $15 \%$. O decreto lei $\mathrm{n}^{\circ} 5.874$, de 2 de Janeiro de 1943, aboliu as quotas de equilíbrio devido à redução das safras. Cessaram as incinerações pelo DNC. Já não havia estoques inaceitavelmente excessivos.

Devido a esse conjunto de dificuldades, era necessário restringir a oferta e produzir a custos reduzidos. $\mathrm{E}$ isso era mais fácil em terras novas. O governo passa, então, a instituir prêmios para incentivar as exportações, dado que os produtores passaram a reter estoques, numa tentativa de forçar uma alta de preços. Com essa expectativa, aumenta ainda mais o interesse por terras novas e o Paraná começa a atrair compradores de terras em grandes proporções e logo depois a acelerar o plantio de cafeeiros. (CMNP, 1975, p.28)

\subsection{As expectativas pós-guerra}

Em relação ao café, ao final da guerra foram efetuadas várias manobras para obter o aumento dos preços, até mesmo com sua redução para permitir maior volume de negócios.

Durante os anos de guerra, a produção brasileira diminuíra bastante, sendo a safra de 1939-1940 a última grande safra. Os estoques estavam reduzidos tanto pela incineração como por efeitos climáticos e redução do número de cafeeiros. Desde 1944 não se queimava café, fora eliminada a quota de equilíbrio e o DNC retirara a proibição do plantio. É a partir deste período que melhor se pôde verificar o incentivo que a alta de preços exerceu sobre a safra paranaense.

Os preços aumentam. As dificuldades de pagamentos internacionais tornavam os cafés mais baratos altamente procurados, o que faz aumentar a procura por cafés brasileiros, mais baratos que os colombianos.

Em julho de 1950 teve início a guerra da Coréia, e os preços cresceram mais depressa devido ao aumento da procura por temor que o conflito novamente desencadeasse uma guerra generalizada.

Em 1951 foi restabelecido o "sistema de defesa". O Brasil impôs um preço mínimo abaixo do qual não seria permitida a exportação e, em caso de pressão por parte dos importadores, o governo voltaria a comprar e estocar café. Em dezembro de 1952, a lei no 1.779 criava o Instituto Brasileiro do Café (IBC), novo órgão executor da política de intervenção no setor e, entre suas atribuições, constava a defesa 
dos preços, inclusive a retirada de café do mercado em caso de necessidade. Dessa forma, voltavam os incentivos ao plantio e à produção.

Os estoques mundiais estavam, nesse momento, reduzidos, devido às geadas e às secas, além das inundações na Colômbia e na Guatemala e das brocas em algumas partes das plantações brasileiras. A ocorrência de novas geadas em 1953 acentuou a tendência para a alta.

$\mathrm{Na}$ verdade, essas geadas foram exageradamente exploradas com o objetivo de forçar ainda mais uma alta na cotação do produto. As primeiras estimativas indicavam uma redução de 3 milhões de sacas e mais a expectativa de que na safra seguinte não haveria produção. Entretanto, a utilização dos estoques dos importadores impediu uma importação maior, o que deteve o aumento no valor do café. Nada mais natural, portanto, que nessa conjuntura novos cafeeiros fossem plantados. A elevação internacional de preços refletiu favoravelmente sobre o comércio interno do café. A tendência da cafeicultura foi a busca acelerada de terras "virgens" de alta fertilidade.

Em 1954 houve um amortecimento da taxa de novas plantações, possivelmente graças à diminuição de terras férteis ou mesmo à existência de um número excessivo de cafezais ainda não adultos. Outra possibilidade é de que um bom número dos cafeeiros plantados em 1954 tenha sido destruído pelas geadas de 1955 e, em conseqüência disso, não apareceu na distribuição etária apurada em 1961. A partir de 1955, os preços internos do café passam a declinar cada vez mais e isso explicaria a queda do ritmo das novas plantações.

$\mathrm{O}$ excesso de café diante da demanda determinou, em 1961, providências do governo brasileiro no sentido de eliminar a produção de excedente. Para tanto, foi criado o Grupo Executivo de Racionalização da Cafeicultura (GERCA), com o programa básico de eliminar 2 bilhões de cafeeiros antieconômicos. Tal medida se justificava em face da superprodução e da deterioração dos preços, especialmente em virtude da entrada das grandes safras paranaenses da década de 50 e início da de 60, e pelo aumento da concorrência externa. Mesmo com o IBC comprando café e realizando estocagem não era possível manter as cifras externas em níveis considerados adequados.

\subsection{Uma nova realidade}

Se neste período os produtores já se encontravam desestimulados devido à instabilidade econômica pela qual atravessava o país, alguns fatores contribuíram para que a produção de café fosse abortada por uma grande quantidade de fazendeiros da época.

A grande geada ocorrida na madrugada de 17 de julho de 1975 (CMNP, 1975, p.104), de proporções jamais vistas até hoje na região dos estados cafeeiros; os 60 dias de seca que se seguiram, o que impediu o início da brotação na maior parte das lavouras; e o período seguinte, de copiosas chuvas, que provocou uma brotação lenta e irregular, foram vistos como um "golpe de misericórdia" na produção cafeeira.

Os cafezais destruídos foram substituídos por pastagens ou por outras culturas. Os que sobreviveram, obvia- mente já não repetiam as mesmas safras. Poucos cafezais foram replantados.

O que observamos então foi que, de uma safra de aproximadamente 2 milhões de toneladas de café no ano de 1960, passamos a 1,5 milhão de toneladas (devido principalmente às medidas de restrição na produção) em 1961. (CANCIAN, 1981) Em 1980 a produção brasileira contabilizou aproximadamente 368 mil toneladas. (IBGE, 19831984, p.87)

Após este período, nas décadas de 80 e 90 o que observamos é a tentativa de substituição das antigas variedades de café por outras mais resistentes e de maior produtividade.

Atualmente, o café adensado ${ }^{4}$ tem sido a maior esperança dos aficcionados por esta cultura, entusiasmando os especialistas, que aguardam para um futuro breve uma ascensão vertiginosa na produção cafeeira. Mas este assunto será tratado com mais profundidade quando abordarmos o município de Jacarezinho.

\section{UMA ABORDAGEM SOCIOLÓ- GICA DA "FRONTEIRA"}

Sempre que se fala em conquista de território e colonização, o que nos vem à mente é a imagem de ampliação das fronteiras. Apesar de parecer lógico, se questionarmos (e este é o objetivo da sociologia) veremos que a questão não é tão simples assim.

Então, o que é a "fronteira" (ou seriam as "fronteiras")?

Poderíamos dizer, utilizando um termo de VELHO (1980, p.114), que sociologicamente a fronteira é "protoplásmica". Ou seja, não é uma linha ou um limite pré-determinado. Tampouco pode ser definida somente como um avanço da população ou um processo unilateral ou unilinear. $\mathrm{O}$ autor é ainda mais específico: "Devemos, na verdade, falar não de uma fronteira, mas de experiências, transações e mutações de fronteiras múltiplas e complexas". (VELHO, 1980, p.114)

Se analisarmos desta forma, a questão assume contornos ainda mais evidentes, uma vez que não podemos fixar nenhuma linha entre homens brancos e índios, civilização e primitivismo, áreas ocupadas e não ocupadas, entre outros exemplos.

E que importância tem a "fronteira" nesse ensaio?

Na verdade não seria a "fronteira" o fundamental, mas a expectativa de ultrapassá-la. Esta possibilidade conduz às relações de trabalho (em nosso caso o campesinato), a um enfraquecimento de uma subordinação estrita e imediata préexistente, pois o objetivo será sempre a conquista de seu próprio espaço. Em outras palavras, o trabalhador (camponês) vê com clareza a possibilidade de "conquistar" seu próprio "território", alterando, assim, os limites da "fronteira". Pode-se dizer que a possibilidade de ultrapassar estas "fronteiras" cria a expectativa de uma ascendência social, que estimulava, via de regra, o colonato das fazendas de café do Norte Pioneiro.

Quando esta expectativa é frustrada e não se aventa a possibilidade de rompimento dos limites da "fronteira", com- 
bina-se o fraco elo de subordinação com a necessidade natural de ascensão social, criando um ambiente altamente propício a uma revolução. A única forma de manter esta situação sob controle é a adoção de um sistema autoritário ou, como foi em várias oportunidades o caso do Brasil, de um capitalismo autoritário. (idem, p.121)

Assim, a "fronteira", ou seus limites, não são estáticos. Inclusive, seu caráter quase intermitente tem feito alguns autores substituírem o conceito de "fronteira" pelo de "frentes pioneiras" e, mais radicalmente, pelo de "frentes de expansão". Nesses casos, até a noção de "pioneira", na medida em que possa implicar uma idéia de ser o primeiro passo numa cadeia de desenvolvimentos, é evitada.

\subsection{O norte do Paraná: frente de expansão ou frente pioneira?}

Para a análise sociológica a respeito da colonização de uma determinada região, não bastam apenas as características históricas de como se deu esta colonização. É necessário entender os outros tipos de relação que estão envolvidas neste processo: relações culturais, econômicas e, obviamente, sociais.

Para que melhor se compreenda que tipo de relações sociais e econômicas estavam envolvidas no processo de colonização do norte do Paraná, sob a ótica da expansão da economia cafeeira e dos lucros dela provenientes, torna-se necessário a caracterização sociológica de dois termos comuns quando se trata da questão agrária: frente de expansão e frente pioneira.

Conforme MARTINS (1975), o que caracteriza uma frente de expansão é justamente o uso privado das terras, em que estas não assumem equivalência em mercadoria. Portanto, a figura central da frente de expansão é a do ocupante ou posseiro. A frente de expansão está integrada na formação capitalista.

Naquilo que sociologicamente denominamos frente de expansão as condições de vida são reguladas pelo grau de fartura e não pelo grau de riqueza. $O$ empreendimento capitalista se encontra "fora" dos componentes da estrutura social. Nesse processo as tensões são menos freqüentes, pois não há propriedade de terras nem é a prioridade o capital.

Essas noções de frente de expansão são indispensáveis para se compreender o alcance e os limites do conceito de frente pioneira.

A frente pioneira instala-se como empreendimento econômico. Passa-se da produção do excedente para a produção de mercadoria. O ponto-chave da implantação de uma frente pioneira é a propriedade privada da terra: ela não é ocupada (como na frente de expansão), é comprada. A renda impõe-se como mediação entre o homem e a sociedade. A terra passa a ser equivalente de capital e é através da mercadoria que o sujeito trava suas relações sociais.

O funcionamento do mercado é que passa a ser regulador da riqueza e da pobreza. A alienação do produto do trabalho no mercado faz com que as expectativas reguladoras do relacionamento sejam constituídas de conformidade com as objetivações da sociedade capitalista.
A diferença entre frente de expansão e frente pioneira gira em torno de um fator: a propriedade privada da terra, ou, renda capitalizada. Esta renda capitalizada, como não poderia deixar de ser, gera tensões.

Dado que a frente pioneira se constitui como empreendimento capitalista, existe uma série de relações sociais pautadas na divisão dos lucros. Essas relações são, na verdade, necessárias à acumulação e reprodução do capital. Daí que a frente pioneira tenha se apresentado sempre como a expressão limite do capitalismo no campo e tenha se apoiado em relações sociais fundamentais não tipicamente capitalistas: escravatura, colonato (no nosso caso) e arrendamento em espécie. Na verdade, o que caracteriza a penetração do capitalismo no campo não é a instauração de relações sociais típicas, formuladas em termos de compra e venda de força de trabalho por dinheiro. O que a caracteriza é a instauração da propriedade privada do território, isto é, a mediação da renda capitalizada entre o produtor e a sociedade. (LUXEMBURG apud MARTINS, 1975, p.50)

Dessa forma, a colonização do Norte Pioneiro, onde está inserido o município de Jacarezinho, não só deve ser considerada como frente pioneira, como também, conforme anotado por PADIS (1981), uma frente pioneira com característica peculiares:

"A um estudioso de movimentos ocupacionais ou de frentes pioneiras de ocupação territorial, não pode passar desapercebido o fenômeno "Norte do Paraná". Poucas notícias existem de acontecimentos processados de forma tão rápida e de efeitos tão surpreendentes que lhe sejam similares". (PADIS, 1981, p.83)

As peculiaridades a que se refere o autor não seriam tão limitadas. NICHOLLS (1971) relata, em seu estudo, que existiriam três características fundamentais da frente pioneira de colonização da região estudada. Em primeiro lugar, por ter sido "espontânea". Em segundo lugar, como também salienta Padis, por revelar o caráter extremamente rápido com que se deu e, por fim, por demonstrar que, apesar da expansão ter sido espontânea (sem a participação de empresas colonizadoras), foi extremamente organizada:

"A maior parte da terra era dividida em grandes propriedades particulares. E a colonização foi feita à medida que estes grandes proprietários de terra dividiam suas propriedades em pequenos lotes que vendiam como lotes urbanos ou estabelecimentos agrícolas". (NICHOLLS, 1971, p.32)

\subsection{O Norte Pioneiro: a "porta de entrada" da cafeicultura e o início da "frente pioneira"}

As regiões onde primeiro se plantaram cafeeiros no norte do Paraná tiveram o processo de povoamento iniciado a partir de meados do século XIX, sendo realizado pela iniciativa de particulares, de modo espontâneo e lentamente. No início do século XX, a penetração se processou com mais 
intensidade e de forma mais regular. Dentro desse processo inclui-se o município de Jacarezinho que, no extremo norte do Paraná, herdava toda a estrutura cafeeira do Estado de São Paulo:

"Ali, o commercio se fazia com as villas de Santa Cruz do Rio Pardo e Pirajú até 1894, por picadões para tropas cargueiras até os portos improvisados na margem esquerda do rio Paranapanema. Os animais transpunham o rio a nado e as cargas eram atravessadas em canoas. Com a construção de uma balsa ligando Ourinhos ao Paraná o commércio passou a ser feito com outras localidades paulistas, entre elas a Estação de Cerqueira César da Estrada de Ferro Sorocabana. Vam dahi o incremento de toda a região, o surgimento de novos portos e novas estradas". 5 (MARTINS apud CANCIAN, 1981, p.54)

Nesse período, as dificuldades encontradas para o plantio de novos cafeeiros eram enormes, além de ser muito difícil conseguir financiamento para aplicação na vasta "selva" que se constituía o norte do Paraná. Daí esta forte ligação com o Estado de São Paulo. Vários estudos apontam esta peculiaridade da cafeicultura paranaense, que se dava pelo fato de haver falta de infra-estrutura no Paraná, um estado ainda pobre, o que não lhe permitia ligar com eficiência a região cafeeira ao litoral. Era natural a tendência em aproveitar-se das condições pré-existentes. Por outro lado, era deles também o capital investido que mantinha as ligações com os grandes bancos daquele estado.

No início da década de 1920, Romário Martins (MARTINS apud CANCIAN, 1981, p.54) nomeava só no município de Jacarezinho 171 fazendeiros e sitiantes principais. Aliás, o município também herdou dos paulistas sua característica fundiária. As fazendas eram sempre grandes propriedades (na época uma exigência da lavoura cafeeira), coexistindo com sitiantes que, estimulados pelo exemplo dos fazendeiros, aderiam à cultura do café, muitas vezes com sucesso, instituindo quase que um sistema de monocultura.

Os proprietários das grandes fazendas eram quase sempre pessoas de nível social elevado, com boa cultura e de fina educação. (idem) Muitos eram médicos, engenheiros, bacharéis. Os arrendamentos eram inexpressivos e o absenteísmo quase inexistente.

Era em Jacarezinho, centro cafeicultor mais importante da região (CANCIAN, 1981, p.58), onde o absenteísmo, embora pequeno, se mostrava mais intenso. Isso leva a crer na possibilidade de os fazendeiros terem propriedades em várias localidades, não sendo necessariamente da região. A exemplo do que ocorrera em São Paulo, uma mesma familia chegava a ser possuidora de várias grandes fazendas. Era patente que a presença do fazendeiro e o planejamento do plantio eram pontos fundamentais para o sucesso da empresa.

Com a expansão das estradas de ferro no norte do Estado do Paraná (até então a Sorocabana, estrada de ferro paulista, chegava até o município de Ourinhos, que faz divisa com Jacarezinho), a produção cafeeira foi responsável por numerosos núcleos urbanos que iam surgindo rapidamente, pouco distanciados uns dos outros, destacando-se, além de Jacarezinho, Cambará, Andirá e Cornélio Procópio, entre outros.

Por ter sido esta região a "porta de entrada" da cafeicultura no norte do Paraná, estes núcleos vão apresentar, a partir de 1910, especialmente Jacarezinho, um ritmo acelerado de desenvolvimento econômico.

Se, de um lado, todo o desenvolvimento dessa região se baseava nas grandes fazendas de café, por outro, o regime de trabalho do "colonato" implantado nas propriedades foi responsável pelos grandes fluxo migratórios para essas localidades, como se pode observar a seguir, ao tomarmos como objeto de estudo o município de Jacarezinho.

\section{O SISTEMA DE COLONATO: UMA RELAÇÃO DE TRABALHO TÍPICA DA CAFEICULTURA}

A partir da década de 30, observa-se em Jacarezinho um verdadeiro rush populacional. Esse fluxo era constituído principalmente de migrantes nacionais (paulistas e mineiros) e alguns grupos de imigrantes estrangeiros, com passagem pelas fazendas de café do Estado de São Paulo. (PADIS, 1981) Na sua maioria, vinham com a família para trabalhar como colonos nas fazendas que estavam em formação na região.

Tal regime de trabalho consistia no contrato de uma família para cuidar de alguns milhares de pés de café por ano, mediante pagamento mensal. "Seu sustento ficava por sua conta, mas as despesas com a lavoura eram de responsabilidade do proprietário. Na época da colheita, o dono do cafezal pagava ao colono e seus familiares por saco de café colhido". (ABREU apud D'INCAO E MELLO, 1975, p.50)

Isso demonstra que se trata de um sistema de exploração de força de trabalho bastante típico de uma região onde há escassez de mão-de-obra. Apesar de haver alguns gastos do proprietário, o sistema expressa a intenção de garantir a mão-de-obra não só durante todo o ano agrícola, máxime na colheita, mas também durante vários anos.

A opção pelo sistema de colonato é associada à sua maior adequação à cultura de café, ${ }^{6}$ em razão de esta cultura necessitar uma quantidade homogênea de mão-de-obra durante todo o ano agrícola. Esta homogeneidade é justificada pelo fato de a colheita de café se efetuar em três etapas e não exigir tanta rapidez, ao contrário de outras culturas de exportação como a soja, o trigo e, também, a cana-de-açúcar.

Se a vida do colono era cheia de dificuldades, com certeza apresentava vantagens ao fazendeiro, especialmente pelo fato de ser fixo no campo. A família recebia do empregador, geralmente sem ônus adicional, casa, água e luz (quando havia), além de ser permitido o cultivo de uma pequena lavoura de subsistência e a criação de pequenos animais. No entanto, o proprietário contava com todos os membros da família para a execução das tarefas sem qualquer custo adicional na produção.

Assim, no início da década de 30, enquanto Jacarezinho e municípios vizinhos apresentaram um acentuado processo de crescimento demográfico, abria-se uma nova 
possibilidade de expansão da cafeicultura mais à frente da região norte do Paraná.

$\mathrm{Na}$ medida em que a fronteira agrícola se movimentava mais para o norte, em direção ao noroeste do estado, o eixo da cafeicultura também mudava, com o surgimento de novos centros produtores, particularmente a região denominada Norte Novo do Paraná, tendo como pólos regionais os municípios de Londrina e Maringá.

Esses aspectos, associados às sucessivas crises da cafeicultura, provocaram alterações significativas na dinâmica econômica da região do Norte Pioneiro, onde se situa Jacarezinho.

É, portanto, dentro desse contexto e com base nos fatos históricos apresentados, que passamos a abordar o objeto principal de nosso estudo: o município de Jacarezinho.

\section{JACAREZINHO: PARADOXO DE PROSPERIDADE E POBREZA}

\subsection{Um pouco de sua história}

As primeiras tentativas de colonização de Jacarezinho de que se têm notícia datam do século passado, sendo um dos primeiros pólos de desenvolvimento agrícola do Estado do Paraná, com sua colonização predominantemente feita por fluminenses, paulistas e mineiros. Ao receberem notícia de solos férteis próprios à agricultura, iniciou-se a migração para esta região do Norte Pioneiro, em primeiro lugar Jacarezinho, e, dentro do contexto estadual, originou-se a comarca de Tomazina. Assim, teve início a colonização regional, com ênfase na agricultura e na pecuária, consolidando-se a economia regional.

Seu relevo é caracterizado como tipicamente de planaltos, alternando planícies e patamares, com características onduladas e variações de altitude entre 300 e 900 metros acima do nível do mar.

Em 1886, o pioneiro fluminense Antônio Calixto promoveu as primeiras derrubadas de matas, dando lugar às primeiras lavouras de subsistência da região.

Em 1888, a família Alcântara, de origem mineira e de comitiva sertanista, fundou a fazenda do Prata, que muito concorreu para o povoamento e desenvolvimento do território, facilitando a penetração do sertão inóspito.

Em 1896 foram abertas as primeiras estradas de rodagem, ligando o novo povoado ao porto de Alcântara, no rio Paranapanema.

Por volta de 1890, aporta à região a terceira leva de pioneiros. As áreas com lavouras e pastagens são ampliadas, surgindo a produção de açúcar, banguê, aguardente e cereais. O café é exportado pela primeira vez em 1896.

O ritmo acelerado do processo deu-se, entretanto, a partir do início deste século, mais especificamente em 1910, com a chegada expressiva de imigrantes e fazendeiros paulistas e mineiros, atraídos pela boa fertilidade do solo.

Em 2 de abril de 1900 há o desmembramento do município de Tomazina, recebendo o nome de Nova
Alcântara (cf. a lei estadual n 522). Mais tarde, em 9 de março de 1904, recebe o nome de Jacarezinho.

\subsection{Alguns aspectos físicos e territoriais im- portantes}

O município localiza-se na região fisiográfica norte do Paraná. Dista 392 quilômetros da capital estadual, sendo inserido na classificação do IBGE como mesorregião 67. Para fins de planejamento, compõe a microrregião estadual n² 279 .

Limita-se ao norte com os municípios de Cambará e Ourinhos (SP), ao sul com Santo Antônio da Platina e Joaquim Távora, a oeste com Barra do Jacaré e a leste com Ribeirão Claro.

Situa-se nas coordenadas $23^{\circ} 09^{\prime} 24^{\prime \prime}$ latitude sul e 49 $58^{\prime} 16^{\prime \prime}$ latitude oeste do meridiano de Greenwich. Sua altitude é de 435 metros acima do nível do mar.

Possui como características climáticas temperatura média no mês mais quente acima de $22^{\circ} \mathrm{C}$ e, no mês mais frio, temperatura média não superior a $18^{\circ} \mathrm{C}$. Caracteriza-se por clima subtropical úmido mesotérmico, verões quentes, geadas pouco freqüentes, tendência de concentração das chuvas nos meses de verão, acima do paralelo $24^{\circ} \mathrm{Sul}$; sem estações secas definidas. As precipitações pluviométricas são na ordem de 1300 a $1500 \mathrm{~mm}$, sendo a última média compensada de $1478,6 \mathrm{~mm}$. A umidade relativa do ar é de 75 a $80 \%$ de média anual.

A formação do solo jacarezinhense é classificado como de alto potencial agrícola. De muito boa fertilidade, reflete sua importância no contexto agrícola estadual. É composto por dezessete tipos diferentes de solo, que resultam da combinação de fatores de origem geológica e de clima quente e úmido, que predomina em grande parte do ano no município. Assim, os solos têm origem na meteorização de caráter químico das rochas, de forma laterítica.

No entanto, os solos municipais apresentam clara dicotomia. Apenas 20\% dos solos podem ser considerados de boa fertilidade natural, pois encontram-se na denominada área de transição entre o segundo e o terceiro planalto, sendo que neste último se encontram os solos mais férteis do Estado do Paraná. Porém, atingem apenas uma pequena área do território em questão.

\subsection{As bases do estudo sociológico - uma proposta de pesquisa}

Com base nas discussões efetuadas anteriormente, interessa-nos, basicamente, entender como a cultura cafeeira foi responsável pelo desenvolvimento de Jacarezinho, e de que forma a decadência desta cultura influenciou na estagnação econômica do município, alterando profundamente as relações de trabalho e a dinâmica de relacionamento entre campo e cidade.

Fica evidente, se utilizarmos os dados dos censos realizados pelo IBGE através dos tempos, que o município de Jacarezinho atravessou um período muito claro de ascensão 
econômica, com um aumento populacional significativo, especialmente entre as décadas de 20 e 60 e, posteriormente, de decadência.

TABELA 1: Progressão censitária - município de Jacarezinho 1900-1991

\begin{tabular}{cc}
\hline Ano & População aferida \\
\hline Censo 1900 (1) & 3.676 \\
Censo 1920 (2) & 13.764 \\
Censo 1940 (3) & 24.528 \\
Censo 1950 (4) & 34.405 \\
Censo 1960 (5) & 42.863 \\
Censo 1970 (6) & 38.741 \\
Censo 1980 (7) & 38.926 \\
Censo 1991 (8) & 40.873 \\
\hline
\end{tabular}

Fontes: 1-7, IBGE (1997); 8, IBGE (1996, p.18).

FIGURA 1: Exposição demográfica - Jacarezinho - 1900-1991*

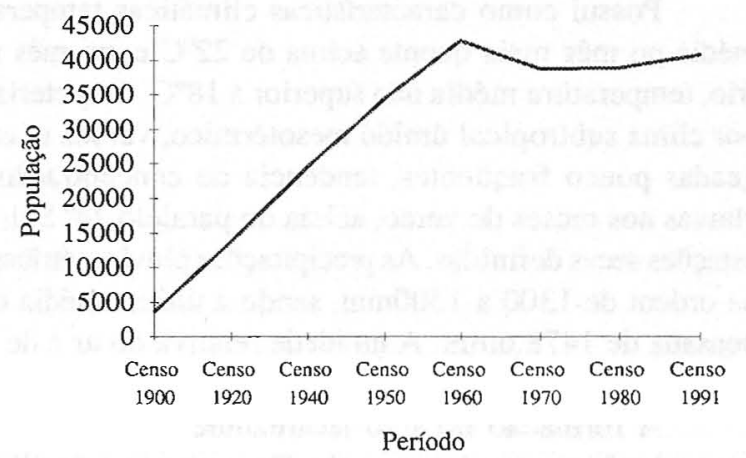

* Não foram realizados censos nos anos de 1910 e 1930.

Fontes: de 1900 a 1980, $\operatorname{IBGE}$ (1997); dados de 1991, $\operatorname{IBGE}(1996$, p.18).

Este período de mudanças no comportamento dos dados populacionais coincide com as principais crises da cafeicultura na região, já discutidas em páginas anteriores, bem como com a paulatina substituição do colonato pela mão-de-obra volante, característica da cana-de-açúcar.

O fim do chamado ciclo do café, no município de Jacarezinho, provocou o inchaço da população urbana e o esvaziamento do campo, conforme descrevemos a seguir.

TABELA 2: Comparativo população urbana/rural - Jacarezinho 1940-1990*

\begin{tabular}{ccc}
\hline Censo & População urbana & População rural \\
\hline $1940(1)$ & 5.135 & 19.393 \\
$1950(2)$ & 8.131 & 26.274 \\
$1960(3)$ & 15.054 & 27.809 \\
$1970(4)$ & 19.103 & 19.638 \\
$1980(5)$ & 23.652 & 15.274 \\
$1990(6)$ & 30.121 & 10.752 \\
\hline
\end{tabular}

* Não houve censo em 1910 nem em 1930; nos censos de 1900 e 1920 as populações não foram separadas.

Fontes: 1-5, IBGE (1997); 6, IBGE (1996, p.18).
FIGURA 2: Comparação entre população urbana e rural Jacarezinho - 1940-1970

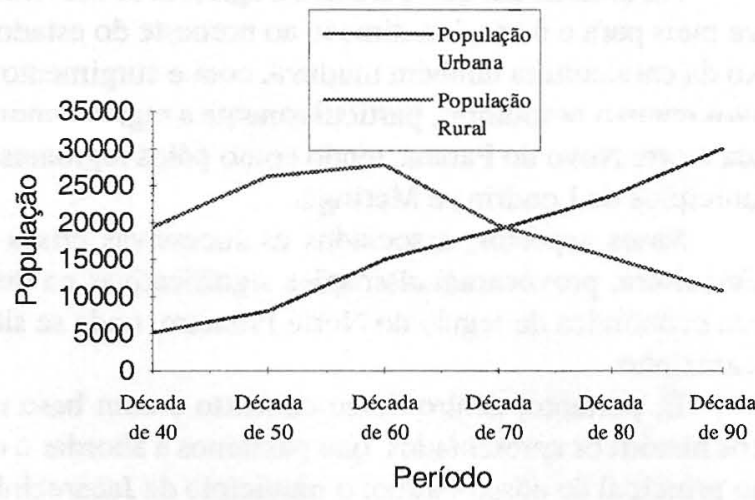

Fontes: de 1940 a 1980, IBGE (1997); 1990, IBGE (1996, p.18).

Em resumo, todo esse processo define uma nova vocação econômica no município, baseada, principalmente, na cana-de-açúcar, tendo como relação de trabalho predominante a mão-de-obra volante — o bóia-fria.

\subsubsection{O trabalhador volante bóia-fria - uma resposta às mudanças na agricultura da região}

O bóia-fria, na definição de D'INCAO E MELLO (1975, p.87), é um tipo de trabalhador que, recebendo por tarefa ou por dia, e trabalhando num ritmo irregular, favorece os interesses do empregador. Existe, em última análise, como decorrência da superabundância de mão-de-obra.

A presença do bóia-fria se traduz por sua permanente disposição para qualquer tipo de trabalho, que se liga diretamente à necessidade de trabalhar para sobreviver.

Outra característica marcante da mão-de-obra volante é o caráter intermitente com que se realiza seu trabalho, fazendo com que esta disponibilidade seja para qualquer tipo de tarefa. O ritmo irregular com que sua força de trabalho é explorada nem sempre the permite continuar produzindo novos meios de subsistência, enquanto consome os recebidos em troca do seu trabalho. Isso lhe confere uma instabilidade econômica que se reflete nas condições de extrema miserabilidade em que vive.

Num detalhadíssimo trabalho sobre o assunto, D'INCAO E MELLO (1975, p.87) elaborou uma fórmula para calcular a renda mensal média do bóia-fria durante um ano. Tal fórmula foi assim constituída:

$\underline{\text { Renda Mensal Média }=\text { renda diária da colbeita } \times 90+\text { renda total dos demais períodos }}$ 12

Onde 90 corresponde aos noventa dias correspondentes à colheita de um ano, onde os salários, por motivos óbvios, são maiores.

Assim sendo, os resultados obtidos foram: 
TABELA 3: Renda mensal do trabalhador volante

\begin{tabular}{c|cc}
\hline $\begin{array}{c}\text { Percentual da renda familiar } \\
\text { mensal em relação à renda- } \\
\text { salário mínima familiar }\end{array}$ & \multicolumn{2}{|c}{ № DE BÓIAS-FRIAS } \\
\cline { 2 - 3 } & Nos absolutos & №s percentuais \\
\hline Até $20 \%$ & 15 & 30 \\
20 a $40 \%$ & 22 & 44 \\
40 a $60 \%$ & 8 & 16 \\
60 a $80 \%$ & 4 & 8 \\
80 a $100 \%$ & 1 & 2 \\
\hline TOTAL & $\mathbf{5 0}$ & $\mathbf{1 0 0}$ \\
\hline
\end{tabular}

Fonte: D'INCAO E MELLO (1975, p.93).

FIGURA 3: Distribuição dos bóias-frias por grupos de renda familiar mensal

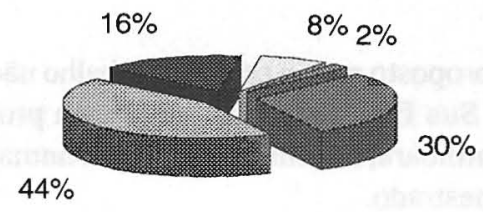

Até $20 \%$

20 a $40 \%$

40 a $60 \%$

60 a $80 \%$

80 a $100 \%$

Fonte: D'INCAO E MELLO (1975, p.93).

Dessa forma, torna-se evidente a condição de miséria vivenciada pela população em questão: $90 \%$ das famílias possuem renda mensal inferior a $60 \%$ da renda mínima.

Logicamente que temos que considerar que o trabalho citado se refere aos trabalhadores volantes de um modo geral, em termos de Brasil. Como dispomos apenas de referências bibliográficas, as adaptações que caracterizam o bóiafria do município de Jacarezinho ficam, de momento, para estudos futuros.

Além disso, há de se ressaltar que o estudo em questão não leva em consideração o caráter de mobilidade característico do trabalhador bóia-fria. Nesse sentido, o estudo realizado por GONZALES \& BASTOS (1977) ganha importância, ao estabelecer que

"o trabalho bóia-fria implica também no deslocamento contínuo dos trabalhadores nas áreas rurais para executarem tarefas (sazonais ou não) em regime de empreitada. (...) Na região cafeeira do Norte do Paraná, verifica-se também que grande parte dos operários agrícolas deslocam-se de uma fazenda para outra, o que implica, muitas vezes, num processo de migração contínua". (GONZALES \& BASTOS, 1977, p.26-27)

Os autores denominam este tipo de trabalho volante de "itinerante", e sua relativa importância neste trabalho refere-se ao fato de que, uma vez que consideramos sua existência, a média de salários calculadas pode sofrer variação. Além disso, poderiam infuenciar também no comportamento populacional apresentado. Entretanto, cumpre ressaltar que essas variações possíveis não alteram de maneira significativa os dados relatados anteriormente.
De acordo com o estudo de D'INCAO E MELLO (1975, p.106-107), a grande maioria dos bóias-frias almeja a condição de assalariado, ou seja, fixar-se em algum tipo de serviço. Procuram o salário fixo não só no meio rural como também no meio urbano, sendo esta uma outra característica que diferencia o bóia-fria do colono. Sendo assim, são numerosas as experiências de trabalho arroladas pelos bóias-frias como serventes de pedreiro ou braçais do serviço público (prefeituras, por exemplo), experiências estas consideradas positivamente, em razão do salário, e negativamente devido ao seu caráter temporário.

Ainda segundo a autora, na seleção para trabalhos em empresas urbanas, o critério de seleção é mais rígido, uma vez que a mão-de-obra é absorvida em condições de maior estabilidade, com contrato por tempo determinado. Dessa forma, são contratados apenas os mais capacitados, não sendo possível conferir oportunidades de capacitação aos que não a têm.

Conforme comprovou o estudo de D'INCAO E MELLO (idem, p.107), o grau de escolaridade entre os bóias-frias é muito baixo.

TABELA 4: Escolaridade - trabalhador volante

\begin{tabular}{lcc}
\hline Escolaridade & No absolutos & Nos percentuais \\
\hline Nenhuma & 35 & 70 \\
Primário Incompleto & 8 & 16 \\
Primário Completo & 5 & 10 \\
SENAI & 2 & 4 \\
\hline TOTAL & 50 & 100 \\
\hline
\end{tabular}

Fonte: D'INCAO E MELLO (1975, p.106).

FIGURA 4: Distribuição dos bóias-frias por grau de escolaridade

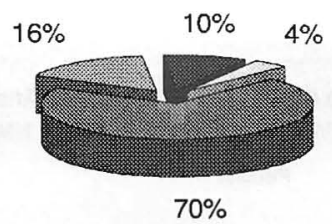

\begin{tabular}{|l|}
\hline Nenhuma \\
Primário \\
Incompleto \\
Primário \\
Completo \\
Senai \\
\hline
\end{tabular}

Fonte: D'INCAO E MELLO (1975, p.106).

A presença proporcionalmente muito maior de indivíduos analfabetos ou semi-analfabetos revela o caráter residual desta população. Os bóias-frias têm consciência dessa condição: pretendem sempre ocupações que não exigem maior qualificação.

O que resta então aos bóias-frias como força de trabalho? Condenados à condição de resíduo do processo de absorção de mão-de-obra, resta aos bóias-frias oscilar entre o trabalho volante na cidade e o trabalho volante no meio rural.

A sazonalidade característica deste tipo de serviço faz com que haja um crescente esvaziamento do campo com conseqüente absorção deste contingente de mão-de-obra excedente pela cidade.

Isso nos leva a afirmar que a pressão imposta pelo sistema capitalista de produção rural transforma o bóia-fria num "marginalizado social". A possibilidade de contar com o trabalhador volante, na economia rural, acelera o processo 
de engrossamento das populações marginais, através da substituição do trabalhador estável pelo trabalhador volante.

A substituição das lavouras pelas pastagens é outro fator que provoca a expulsão do homem do campo para a cidade. Como a pecuária (geralmente de corte) exige um menor contingente de pessoal, esta substituição acarreta também sobra de mão-de-obra que, invariavelmente, migra para a cidade em busca de melhores condições ou de, pelo menos, um emprego digno.

Além disso, a comprovação da máxima capitalista de que existe a tendência de o grande proprietário incorporar o pequeno, contribui em muito para a acentuação do êxodo rural. E isto é característico do município de Jacarezinho, conforme tentaremos expor a seguir.

TABELA 5: Propriedades rurais - Jacarezinho - 1920-1985

\begin{tabular}{ccc}
\hline Período & Área média (Hec.) & No de propriedades \\
\hline Ano de 1920 & 79,5 & 81 \\
Ano de 1935 & 40,9 & 333 \\
Ano de 1942 & 37,6 & 381 \\
Ano de 1985 & 74,8 & 761 \\
\hline
\end{tabular}

Fontes: Censo Agrícola do Paraná, 1920 (apud CANCLAN, 1981, p.72); levantamento cafeeiro, DNC, 1935 (idem); levantamento cafeeiro, DNC, 1942 (idem); IBGE (1988).

FIGURA 5: Tamanho médio das propriedades rurais $\mathrm{x}$ período Jacarezinho - 1920-1985

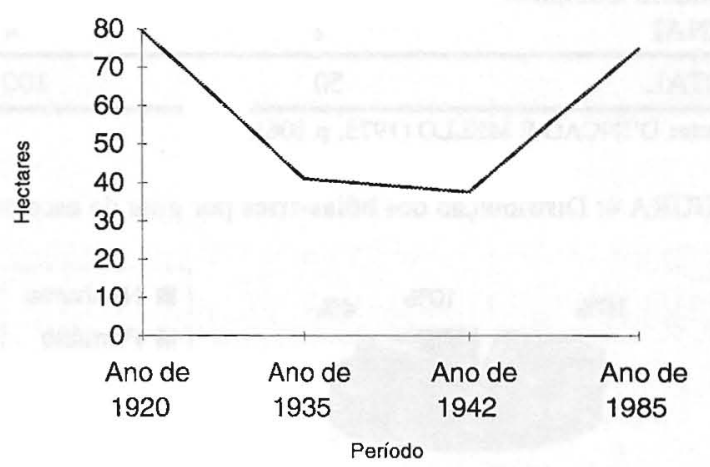

Fontes: Os dados dos anos de 1920 a 1942 foram extraídos de CANCIAN (1981); os dados de 1985 foram extraídos do censo agropecuário do IBGE referente ao ano de 1985 (IBGE, 1988).

O gráfico anterior nos dá uma idéia, apesar da precariedade dos dados, de que existe realmente uma tendência de efetivação de grandes propriedades no município, o que significa, sem dúvida, maior contingente de trabalhadores rurais se deslocando para a zona urbana e, com isso, um aumento de trabalhadores volantes bóias-frias.

Estes dados nos levam a acreditar que as sucessivas crises da cultura cafeeira, ao provocarem mudanças substanciais nas relações de trabalho, influenciaram significativamente na dinâmica da cidade e nas relações entre meio rural e meio urbano.

Mais especificamente, as reflexões até aqui realizadas nos levam a supor que:

1) O desenvolvimento da cafeicultura no norte do Paraná, fruto da expansão cafeeira paulista no início do século, foi decisivo para o desenvolvimento econômico e social de Jacarezinho.

2) A substituição da cafeicultura pela cana-de-açúcar nesse município está relacionada ao desenvolvimento capitalista nacional e regional.

3) O rompimento das relações de trabalho da cafeicultura (colonato) e sua conseqüente substituição pela mãode-obra volante influenciaram significativamente na dinâmica das relações entre campo e cidade, com o aumento do êxodo rural, da pobreza e inchaço da população urbana da cidade de Jacarezinho.

\section{CONSIDERAÇÕES FINAIS}

O objetivo proposto para o presente trabalho não visa esgotar o assunto. Sua finalidade é embasar uma proposta de trabalho que continuará, nos mesmos moldes, numa futura dissertação de mestrado.

Tendo em vista a abrangência do assunto, é necessário que não percamos de vista dois aspectos: primeiro, que o nosso objetivo é uma análise sobre um espaço delimitado correspondente ao município de Jacarezinho; e, segundo, que a abordagem a ser feita, apesar de em alguns momentos enfatizar a história, tem caráter sociológico e, portanto, deve levar em consideração o processo mais amplo de desenvolvimento do capitalismo nacional.

Como é impossível negar que a colonização norte paranaense foi fruto da necessidade de expansão da cafeicultura paulista e dela herdou todas as características, conceitos já mencionados neste trabalho como os de "fronteira", "frente de expansão" e "frente pioneira" merecerão um maior aprofundamento numa futura continuação.

Na seqüência, abordaremos a questão específica da mão-de-obra utilizada na cafeicultura, ou seja, o colonato. Nesta fase, o processo migratório para a região, a substituição do colonato pela mão-de-obra volante, as modalidades de contrato, seus meios de vida e subsistência e as dificuldades de sobrevivência serão aspectos que deverão ser analisados mais detalhadamente.

Para tanto, serão utilizados análises históricas, dados estatísticos e estudos comparativos que possam contribuir para um melhor entendimento do proposto.

Nesse trajeto, ao tomar como base a história da cafeicultura, a intenção é compreender a inserção do município de Jacarezinho nesse processo, como se deu o esvaziamento do café como alternativa econômica, as mudanças nas relações entre cidade e campo e o consequiente empobrecimento da população.

Além disso, abordaremos, também, as alternativas de desenvolvimento criadas, principalmente a cana-de-açúcar, e a tentativa de transformar o município em pólo educacional. Para tanto, deveremos apoiar-nos em entrevistas realizadas junto aos pioneiros e aos que tiveram a oportunidade de administrar o município no passado. Por fim, traçaremos um paralelo das conseqüências da atual política, ou seja, a 
tentativa de desenvolver no município o setor industrial e de abandonar por completo o meio rural. Dedicaremos, também, uma atenção especial à cultura do café adensado e a expectativa de "volta ao passado" que com ele se cria.

Com isso, pretendemos clarear alguns aspectos importantes sobre as transformações na estrutura agrária do município, as mudanças nas relações de trabalho e os aspectos socioeconômicos que envolvem a dinâmica entre meio rural e meio urbano. Por fim, queremos oferecer, com o aprofundamento deste estudo, algumas propostas que possam servir de subsídios para os atuais e futuros planejadores do município.

\section{NOTAS}

1 Existem hoje no município de Jacarezinho duas grandes usinas de açúcar e álcool, a Cia. Agrícola Usina Jacarezinho e a Destilaria de Álcool Corrêa Arruda Ltda. (DACALDA). Havia uma outra, a Destilaria de Álcool Major Infante (DAMISA), hoje desativada.

2 As três primeiras classificações foram estabelecidas por CANCIAN (1981). A quarta classificação foi inclusa com base em observações e dados do desenvolvimento da cafeicultura paranaense pós-1970.

${ }^{3}$ Nesse contexto, não há como negar que a cafeicultura paranaense e a conseqüente colonização do norte do Paraná foram frutos da expansão espontânea da cafeicultura paulista em busca de novas oportunidades.

${ }^{4}$ O café adensado constitui-se uma nova variedade de café, mais rústico $\mathrm{e}$, portanto, mais resistente às variações climáticas e de solo. Além disso, permite 20 mil pés por alqueire, enquanto as variedades plantadas em épocas passadas permitiam apenas 5 mil pés por alqueire, o que gera, conseqüentemente, maior produção em uma menor área. O "café adensado" vem sendo plantado em toda a região norte do Paraná.

5 Alusão às cidades paulistas de Pirajú, Santa Cruz do Rio Pardo e Cerqueira César.

- Por aí atesta-se sua especificidade e consequëente valorização do trabalhador rural "especialista".

\section{REFERÊNCIAS BIBLIOGRÁFICAS}

CANCIAN, Nadir A. Cafeicultura paranaense: 1900-1970. Curitiba: Grafipar, 1981.

CMNP-COMPANHIA MELHORAMENTOS NORTE DO PARANÁ. Colonização e desenvolvimento do norte do Paraná. 1975.

D'INCAO E MELLO, Maria Conceição. O "bóia-fria": acumulação e miséria. Petrópolis: Vozes, 1975.

GONZALES, Élbio \& BASTOS, Maria Inês. "O trabalho volante na agricultura brasileira". In: SINGER, Paul. Capital e trabalho no campo. São Paulo: Hucitec, 1977. p.25-47.

IBGE-INSTITUTO BRASILEIRO DE GEOGRAFIA E ESTATÍSTICA. Sinopse preliminar do censo agropecuário, 1970-1980. Rio de Janeiro: IBGE, 1983-1984.

Sinopse preliminar do censo agropecuário, 1985. Rio de Janeiro: $\mathrm{BBGE}, 1988$

Dimensões das Carências Sociais: informações municipais. Rio de Janeiro: IBGE/IPEA, 1996.

. Dados demográficos do município de Jacarezinho - 1900-1981. Jacarezinho: IBGE, 1997.

MARTINS, José de Souza. $O$ cativeiro da terra, 2.ed. São Paulo: Lech, 1981.

Capitalismo e tradicionalismo. São Paulo: Pioneira, 1975. o Estado do Paraná". Revista Paranaense de Desenvolvimento, n.26, p.30-34, set./out. 1971.

PADIS, Pedro Calil. Formação de uma economia periférica: o caso do Paraná. São Paulo: Hucitec, 1981.

VELHO, Otávio Guilherme. Capitalismo autoritário e campesinato. São Paulo: Difel, 1980.

NICHOLLS, Willian H. "A fronteira agrícola na história recente do Brasil: 